I Universidad Nacional de San Martín (UNSAM), Buenos Aires, Argentina

m_hornes@hotmail.com

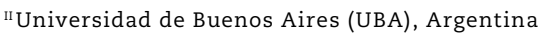

merkrause@gmail.com

Martín Hornes '
Mercedes Krause "

\title{
SIGNIFICADOS E USOS DO DINHEIRO: SETORES MÉDIOS E POPULARES DE BUENOS AIRES
}

Assistimos à emergência de um novo campo de estudos sociais que transcende a "grande divisão" disciplinar pretendida pela economia perante as demais ciências sociais ao longo do século XX (Florence Weber, 2009: 30; Neiburg, 2010: 230). Trabalhos recentes propõem abordar desde a problematização da denominada economia solidária (Motta, 20I0), como a própria noção de mercado (Lorenc Valcarce, 20I 2; Callon, I998) e os considerados mercados "alternativos" ou de escambo (Luzzi, 2005). Pode-se assinalar também estudos sobre o consumo (Figueiro, 20I3; Miller, I998), a proliferação dos sistemas de créditos e as novas tecnologias financeiras (Müller, 20I4; Wilkis, 20I4), os processos inflacionários (Neiburg, 2005, 2007, 2008) e, inclusive, as crises econômicas locais e internacionais (Théret, 2007; Lapavitsas, 2009).

Estas indagações têm sido acompanhadas pelo desafio de reabilitar os significados do dinheiro para além do restrito âmbito econômico e de sua capacidade como meio de mudança, forma de pagamento e reserva de valor (Théret, 2008). Desde a metade do século XX, a literatura antropológica e sociológica tem demonstrado os usos múltiplos do dinheiro e seu caráter irredutível a apenas uma esfera social - o mercado - e a um tipo de vínculo social - as relações mercantis (Polanyi, I957; Dalton, I967; Bohannan, I967). A antropologia econômica indicou de modo pioneiro que as transações mediadas pelo dinheiro ultrapassavam os espaços sociais denominados como "mercado". Observa-se atualmente um campo de estudos consolidado em torno de uma 
socioantropologia do dinheiro (Bloch \& Parry, I989; Dodd, I994; Guyer, I994, 2004; Weber \& Dufy, 2009; Maurer, 20I2; Zelizer, 2009, 20I I). Os trabalhos de Zelizer (2009, 20I I) marcaram o início das reflexões sobre os significados sociais do dinheiro demonstrando que, longe de ser um elemento homogêneo, impessoal e afetivamente neutro, seus sentidos são construídos a partir dos diferentes pontos de vista dos atores sociais em determinados contextos de interação e de transações específicas. Suas análises destacam a inconsistência de supostos "mundos hostis" (Zelizer, 20I I: 45) que separam a economia das relações pessoais e íntimas, e nos convidam a observar as transações monetárias considerando os valores morais, pessoais e familiares que intervêm na construção dos significados do dinheiro (Wilkis, 20I3).

A perspectiva predominante no campo dos estudos sociais da economia nos aproxima do tema central deste artigo: analisar os significados e usos sociais do dinheiro em setores médios e populares da Área Metropolitana de Buenos Aires. Interessa-nos reconstruir as categorias e os sentidos mobilizados pelos atores para se referirem aos significados e usos sociais do dinheiro, a partir da observação de suas práticas econômicas ordinárias (Weber, 2002). Longe de qualquer perspectiva utilitarista, evocamos as definições propostas por Neiburg (2008: 94) e Florence Weber (2002: I52) sobre "práticas e ideias ordinárias" ou "cálculos ordinários" respectivamente, para examinar o conjunto de "racionalidades ou sentidos práticos" que os agentes mobilizam para definir seus orçamentos familiares, negociar os significados do dinheiro e avaliar suas respectivas origens e destinos. ${ }^{\mathrm{I}}$

Em consonância com as perspectivas interpretativas desse campo de estudos e dos possíveis enfoques teóricos sobre as classes sociais, elegemos o enfoque weberiano sobre os comportamentos e práticas sociais e a interpretação dos sujeitos sobre sua própria realidade. ${ }^{2}$ Max Weber (I964) define a análise sociológica como a compreensão e interpretação do sentido subjetivo que os atores atribuem a suas respectivas ações. Ao mesmo tempo, farão também parte de nosso esquema analítico as noções de situação biográfica (Schutz, 2003) e habitus econômico (Bourdieu, 2000, 2003). Retomando a tradição da fenomenologia social, ambos os autores coincidem na necessidade de interpretar as decisões e ações dos sujeitos dentro de seus próprios marcos de interpretação sobre o mundo social, com base nos esquemas adquiridos com as experiências vividas e levando em consideração a avaliação de suas expectativas ou oportunidades sobre futuros desejados ou possíveis.

O texto resulta do encontro da pesquisa qualitativa de tipo biográfica com a pesquisa etnográfica e aborda distintos grupos familiares no interior de dois grupos sociais também diferentes - setores médios e populares. ${ }^{3}$

A pesquisa qualitativa de tipo biográfica se insere na área de estratificação social, e se dirige ao estudo das práticas cotidianas de classe a partir de uma perspectiva fenomenológica, focalizando dois temas-chave para a repro- 
dução social: a educação e a saúde familiares. O trabalho de campo dividiu-se em duas etapas: a primeira, entre setembro de 2009 e fevereiro de 2010 , e a segunda, durante janeiro e fevereiro de 2013. Realizamos entrevistas biográficas semiestruturadas com os pais ou mães de vinte famílias de diferentes estratos de classe média e completamos suas árvores genealógicas utilizando-as como ferramenta de análise e produção de dados. ${ }^{4}$ Analisamos seus relatos seguindo as pautas da análise temática (Boyatzis, I998), com um software especializado para a análise de dados qualitativos.

O trabalho de campo se realizou durante três anos em um bairro popular do Município de Avellaneda, localidade situada ao sul da Cidade de Buenos Aires. ${ }^{5}$ A entrada no campo estava garantida desde 2008 mediante o contato com distintos agentes estatais e trabalhadores sociais pertencentes a um programa de Transferências Monetárias Condicionadas (TMC) destinado a adolescentes em situação de vulnerabilidade social (Hornes, 20I4). O desenvolvimento de diferentes pesquisas nos manteve vinculados ao acompanhamento econômico de mais de 20 lares beneficiários de diversos programas de TMC.

Em uma primeira parte, descreveremos os orçamentos de diferentes lares de setores médios e populares observando como seus membros organizam, distinguem e classificam o dinheiro. Em uma segunda parte, analisaremos as avaliações morais feitas sobre as origens do dinheiro, e demonstraremos como distintas tipificações e juízos morais incidem sobre seus usos. Nas conclusões refletiremos sobre os significados do dinheiro ao analisar como os esquemas diferenciados de percepção e apreciação iluminam sentidos e usos plurais do dinheiro nos setores médios e populares.

\section{ORÇAMENTOS, EQUAÇÕES E USOS DO DINHEIRO}

Silvia, 45 anos, analista de contratos no setor privado, duas filhas.

A família de Silvia é monoparental, do bairro portenho de Congreso. Ela tem 45 anos e trabalha em Retiro; é analista de contratos em uma empresa privada do ramo da saúde. Casou-se em I 995 com um companheiro de trabalho e se divorciou em 2003. Desse matrimônio tem duas filhas, de 9 e I4 anos. Atualmente, está preocupada com a questão do Facebook e o acesso à Internet das filhas adolescentes. Durante a entrevista falou de sua preocupação com "o social", dentro do qual incluiu tanto os roubos e a insegurança quanto "a noite", o álcool e as drogas, bem como as "amizades que não estudem ou que não pensem no futuro". Suas filhas frequentam uma escola privada de dupla jornada, já que a organização da casa é um tema delicado para Silvia: "[minha filha] entra no colégio às sete e meia e sai às seis e quinze, se eu conseguir chegar para buscá-la". Como em outras famílias de setores médios, Silvia considera altos os gastos em educação e saúde. Embora não explicite se somente ela arca com os pagamentos ou se os divide com o ex-marido, inclui como gastos na educação 
e saúde das filhas tanto a escola privada quanto o lazer, o clube e outros. No entanto, não os menospreza perante outros tipos de consumo:

- Os gastos da família na saúde e educação são altos?

- Tranquilamente. Levarão... [risos] e eu diria a você que $60 \%$ podem levar, hein! $60 \%$ da renda seguramente, seguramente, porque falamos da educação, isto da educação, lazer, tudo, sim. Sim. Sim, sim.

- É algo que você cortaria?

- Não. Não. Cortaria internet, cortaria a tv a cabo, cortaria toda uma série de coisas, mas não. A não ser que eu fique sem... obviamente esteja no limite e fique sem trabalho, obviamente, mas não... Não, eu creio que [é] o melhor investimento que posso dar às minhas filhas, certamente. Não, isso não cortaria.

Igualmente, Silvia considera que contar com serviço doméstico "é absolutamente fundamental", ainda que por ora isso não possa acontecer. Não conta com a ajuda de seu ex-companheiro a não ser nos dias previamente ajustados, por isto, em caso de emergências recorre a sua mãe. Normalmente, o trabalho familiar cotidiano recai sobre ela, o que implica deixar de lado as próprias necessidades, "porque isto que te digo também tem um custo. Tudo isto de oferecer um clube, de oferecer isto... custo, horários [...] e chega um momento que giro em torno delas de verdade [risos]. A vida passa a ser elas [se refere às suas filhas]".

Andrea, 45 anos, publicitária autônoma sem empregados, dois filhos.

A família de Andrea experimentou uma forte queda do seu nível de vida durante os últimos anos, e um descenso intergeracional entre diferentes estratos da classe média. Andrea, de 45 anos, vem de uma família de classe média católica, seus pais eram donos e vendedores de uma livraria-loja de brinquedos no bairro de Flores. Agora vive em uma casa, onde também trabalha de forma autônoma, a poucas quadras da estação de Constitución, Cidade Autônoma de Buenos Aires (CABA). Ela e o marido têm sua própria empresa de publicidade e propaganda desde 200I, quando perderam seus respectivos empregos. ${ }^{6}$ Além disso, desde então se encontram sem seguro de saúde pois não podem arcar com um plano particular.

Andrea vê diferença entre escolher o que se prefere e projeta e ter que optar por uma única alternativa. No que diz respeito à saúde e à educação da família, "optar" significa aceitar a falta de dinheiro e utilizar os serviços públicos de que desconfia, o que implica o risco de entregar ao destino e "cruzar os dedos". Depois de explicar esta distinção com um exemplo referido ao planejamento político, Andrea nos conta como a queda do nível de renda familiar obrigou-os a "optar" entre o acesso à saúde e o acesso à educação privadas, dois setores que consideram prioritários:

Por ora não tenho orçamento para cobrir essa questão [a cobertura médica do plano de saúde]. Ou seja, nos colocaram na decisão de se "seguro saúde ou educação?" "Educação" [risos]. Aí sim, optei. [...] [Em] uma época tivemos seguro saúde 
e, depois já não se pôde manter e optamos por seguir adiante com a questão educacional dos meninos, [...] e o outro [é] cruzar os dedos [para que nada aconteça].

De seu relato se destaca que, embora em situação de crise econômica familiar, ela segue valorizando a saúde e educação privadas, mas dando prioridade à educação para que seus filhos não percam o círculo de pertencimento e relações sociais já construídas. O contrário acontece no caso de outra mãe de classe média, que, diante de uma crise econômica familiar, optou por mudar seus filhos para um colégio público, mas não deixou "nem o plano de saúde, nem o clube, (...) mesmo nos piores momentos".

\section{Nancy, 32 anos, beneficiária de distintos programas de TMC.}

Mãe de cinco filhos.

No início de 20 I I, Nancy tinha uma obra em andamento em sua casa. Havia terminado de construir a laje, mas as placas de isopor e algumas estruturas de ferro ainda estavam aparentes. A porta de entrada, de chapa galvanizada branca, brilhava como nova, ainda sem o batente. A casa contava com uma pequena cozinha com um quarto contíguo, de seis metros quadrados, com duas camas beliche, e um banheiro em construção no fundo da casa. As paredes estavam sem tinta e em algumas partes faltava o reboco. As instalações eram muito precárias, alguns móveis eram novos e outros estavam caindo aos pedaços.

Nancy tinha uma economia bastante ajustada, apoiada em sua criatividade para as práticas econômicas (Gaggioli, 20I4). Suas atividades laborais eram variadas: desde fazer faxina em casas de família até vender roupa íntima por catálogo. Também recebia diferentes rendimentos por ser beneficiária de programas de TMC. Costumava trabalhar várias vezes por semana limpando a casa de uma pessoa conhecida do bairro: "às vezes me chama todos os dias, e me convém, porque me paga i3 pesos a hora, por agora... porque é uma casa muito simples e não me mato. É uma senhora aqui da Igreja”. Por outro lado, Nancy vendia roupa íntima masculina e feminina por catálogo e encomenda nas zonas próximas ao centro da Cidade de Buenos Aires:

Trabalho muito com as pessoas [que fazem o serviço] da limpeza. As pessoas do edifício "Condor", toda essa parte daí. Eu lá na favela [villa] 3i tenho a família do pai dos meninos, compro ali e levo a revista, e depois do trabalho passo para oferecer. No Retiro tenho quase todos os clientes, eu levanto de 40 a 50 pedidos.

Desde o mês de agosto de 20Io, Nancy faz parte do programa Ingreso Social con Trabajo "Argentina Trabaja" (Renda Social com Trabalho "Argentina Trabalha").7 Também recebe a Asignación Universal por Hijo para la Protección Social - AUH (Subsídio Universal por Filho para a Proteção Social) ${ }^{8}$ devido à idade e à escolarização de seus 5 filhos, desde o mês de dezembro de 2009 .

Ela sempre mostrava preocupação com os filhos, um incansável cuidado para que não "lhes falte nada" e "poder deixar- lhes algo". Para ela, resolver sua situação habitacional era a prioridade: 
Eu quero tudo, mas o orçamento não dá. Quero comprar um jogo de sofás, e depois digo: para quê? Se ainda tenho que levantar o andar de cima, comprar a cerâmica, e tenho que fazer a escada. Penso: O que é que eu faço? A escada ou a parte de cima? Não sei, é uma confusão na cabeça.

Para resolver as preocupações relacionadas ao término da casa e a seus rendimentos econômicos, Nancy recorre a todo tipo de movimentação com o dinheiro. Da quantia proveniente do programa "Argentina Trabaja", ela utiliza a maior parte para o financiamento da compra de móveis usados ou alguns eletrodomésticos para a casa. Recorre sempre ao mesmo lugar de venda de artigos usados e financiados em prestações graças à apresentação de distintos comprovantes da sua situação de beneficiária de um plano ou programa social:

Desde que comecei a receber o PEC (Programa de Empleo Comunitario) [Programa de Emprego Comunitário] que ele vai todo diretamente para comprar no "Tano Muebles", aqui na [Avenida] Centenario. Eu comecei com o recibo do plano de I50, isso e o DNI [Documento Nacional de Identificação]. Me davam... comprei primeiro um nebulizador... Depois uma bicicleta para eles, depois os armários de roupa, os colchões, depois a tv, depois a geladeira, o fogão, e assim. Máquina de lavar, máquina de secar, tudo tirei a crédito.

O crediário é para Nancy talvez a única possibilidade de acesso a tais bens: "senão não vou ter nada, porque eu, queira ou não, tenho que pagar [através ] de crédito". ${ }^{9}$

A AUH ocupa outro lugar no orçamento de Nancy: "o primeiro que eu faço, tiro o dinheiro e depois vou comprar. Tudo o que houver". Ainda que não costume utilizar o dinheiro para conseguir crédito porque "não serve para crédito", era habitual que comprasse alguns materiais de construção ou alguma divisória ou esquadria para a obra da casa.

\section{Patrícia, 38 anos, beneficiária de distintos programas de TMC, duas filhas.} Atualmente Patrícia convive com seu namorado, Marcelo, sua sogra, de uns 70 anos aproximadamente, e duas filhas, de 8 e 5 anos de idade. A casa de Patrícia e Marcelo localiza-se na zona do bairro denominado pelos vizinhos como "os depa”, oriundo de uma urbanização do Plan Federal de Viviendas [Plano Federal de Moradias $]^{\text {Io }}$ realizado há aproximadamente i I anos. “Os depa” é, portanto, a categoria nativa utilizada pelos vizinhos do bairro para se referirem a um setor no qual foram construídos apartamentos.

O orçamento da família é composto de rendimentos variados com forte participação do dinheiro proveniente de diferentes programas de TMC. Patricia trabalha três vezes por semana como empregada doméstica em uma casa de família, recebendo 360 pesos por mês, “ou seja... nada”, ela afirma. Também recebe a AUH por suas duas filhas menores, e o Plan Más Vida [Plano Mais Vida] ou "os 80 [pesos] dele" [se refere ao dinheiro transferido pelo plano], como costuma mencionar Marcelo. ${ }^{\text {II }}$ Marcelo, além disso, é beneficiário do programa "Argentina Trabaja", pelo qual recebe uma transferência condicionada de I.200 
pesos mensais, e trabalha cerca de 4 horas diárias nas imediações do bairro. Por último, sua mãe ganha uma pensão de aproximadamente 700 pesos. Como costuma afirmar Patrícia: "com isso nos remediamos".

"Remediar" para Patrícia significa disputar com Marcelo os usos do dinheiro pertencente ao orçamento da casa. Ela sempre quer "se dar um prazer" - isto é, consumir algum bem por prazer e sem um fim específico - ou "arrumar a casinha", mas Marcelo insiste em "lidar com cuidado com o que se ganha com o suor do rosto". Então, Patrícia é quem "controla" o orçamento da casa, já que "sabe o que faz falta... sabe mais ou menos o que se necessita na casa". Esse "controle" implica considerar os detalhes dos rendimentos de que ela pode dispor e ir distribuindo o dinheiro entre a alimentação, os impostos, o cuidado com suas filhas, e o sonhado embelezamento da casa. Patrícia separa os distintos destinos do dinheiro do orçamento porque sabe que "Marcelo guarda em uma latinha, e quando chega o fim da semana ele gosta de tomar sua cerveja por aí". Ela vê nisso a possibilidade de negociar o uso do dinheiro proveniente da AUH e reclamar sua posse:

O cara sai às 5 da tarde e não volta até a uma da madrugada. Pense, se acontece algo nesse trajeto, eu, como me viro? Isso é o que ele não entende, não, [eu digo:] você quer para gastar! Não, imagina, Deus não permita que aconteça uma desgraça, e eu tenha que sair às carreiras pedindo dinheiro aos vizinhos.

Ao separar certos "dinheiros" Patrícia pode fazer algumas coisas às escondidas ou na ausência de Marcelo: "eu digo para ele: querido, vamos, vamos, Marcelo. Mas não adianta. Eu sei que as coisas não estão para se ficar dando prazeres mas, bom, compra alguma coisa para você. Eu aproveito quando o patrão não está para comprar alguma coisinha, comer um iogurte com as meninas".

Quer se trate de "investimentos" ou de "escolhas", para "deixar algo" para os filhos ou poder "ter um prazer" com eles, em todos os casos descritos nos deparamos com diferentes categorias por meio das quais os setores médios e populares falam dos distintos dinheiros que compõem seus orçamentos. Trata-se daquilo que Zelizer reconheceu como formas de marcação do dinheiro através "das quais as pessoas identificam, classificam, organizam, usam, segregam, produzem, desenham, guardam e inclusive decoram o dinheiro, à medida que vão enfrentando seus múltiplos vínculos sociais" (Zelizer, 20I I: I3).

Interessa-nos identificar a presença destas diferentes formas de marcação do dinheiro em setores médios e populares para demonstrar como os atores organizam seus orçamentos com categorias de senso comum. O dinheiro é assim classificado segundo sua origem e destino, diferentes representações ou práticas a ele associadas, formas diversas de denominá-lo, distintos vínculos pessoais ou familiares.

Os registros de entrevista dos setores médios indicam como esses grupos enfatizam o dinheiro e percebem sua relação com o acesso a distintos setores e serviços de saúde e educação, vistos como socioeconômica e geografi- 
camente estratificados. Os serviços públicos de saúde e educação são gratuitos na Argentina, e assim o significado do dinheiro aparece conjuntamente com uma tomada de consciência acerca das necessidades próprias e de outros, como um indicador de quais serviços estão ou não ao alcance de suas famílias. De algum modo, estas famílias interpretam a oferta de qualidade nos serviços de saúde e educação como desigualmente apropriada segundo a posição de classe e a renda de cada família. O dinheiro lhes oferece liberdade de escolha e de acesso, sua falta se manifesta como incerteza. Assim, assume um sentido de potencialidade ao permitir a apropriação de oportunidades - "investir", "escolher" ou "optar". Nesse sentido, Hout (2008) afirma que mais renda significa mais opções.

Esse aspecto introduzido por Hout nos aproxima das reflexões sobre os significados do dinheiro nos setores populares. Nos registros de pesquisa relativos a esses setores, a carência econômica impacta suas avaliações e os obriga a resolver situações de maior urgência (alimentação, moradia e a aquisição de bens móveis) do que aquelas que preocupam os setores médios. Entretanto, as formas de marcação do dinheiro não desaparecem, mas, sim, se adaptam às suas racionalidades práticas e ao conjunto de oportunidades atuais e expectativas de futuro. Apesar de nos lares dos setores populares predominarem os baixos e instáveis rendimentos ou jornadas de trabalho informais, seus membros administram seus dinheiros, poupam, investem e se endividam enquanto lutam com graves problemas como a subsistência diária, os empréstimos, favores e ajudas dadas a, ou recebidas de, familiares (Guérrin, 20I4; Villareal, 2010).

Portanto, as lógicas que organizam os significados do dinheiro e estruturam os orçamentos dos setores médios e populares não se reduzem à quantidade, mas dizem respeito também às situações biográficas (Schutz, 2003) ou aos habitus econômicos (Bourdieu, 2000, 2003) através dos quais os atores decidem e realizam equações monetárias e avaliações morais. Apesar de distintas condições materiais incidirem sobre tais cálculos e juízos, vemos um denominador comum entre os setores estudados: seja para "investir" na educação dos filhos, seja para finalizar a casa e poder "deixar-lhes algo", ambos fazem uso de uma forma de "dinheiro cuidado" (Wilkis, 2013). Trata-se de um dinheiro que organiza seus pontos de vista e que, resguardando os valores morais familiares, se destina a gastos relacionados com a reprodução familiar.

Como assinalava Simmel, "quando alguém possui dinheiro, não só dispõe da propriedade deste [...], como também lhe é assegurada a posse de muitas outras coisas" (Simmel, 2010: 22). Desta perspectiva, o dinheiro possibilita o acesso "àquilo que a pessoa deseja ou crê positivo para si mesma e sua família" (Sautu, 200I: 65). O "dinheiro cuidado" que identificamos nos orçamentos de setores médios e populares nos permite afirmar que suas ações significativas e decisões econômicas resultam de avaliações monetárias e morais que va- 
riam conforme as condições do grupo social de pertencimento. Certamente encontramos orçamentos mais estáveis e folgados nos dois primeiros relatos de famílias de classe média. No entanto, em nenhum caso faltaram referências a desejos que gostariam de realizar futuramente, como contratar uma empregada doméstica, obter um plano de saúde, ou desfrutar de um iogurte com os filhos. Existem também pequenos prazeres decididos em função de um orçamento familiar e de um contexto social restritivos. Apesar disso, o "dinheiro cuidado" nos permite observar como cada grupo familiar busca cuidar de suas finanças e bens materiais sem negligenciar os valores pessoais, morais e familiares que desejam transferir entre gerações, afirmando a relevância de cuidar da saúde, do lazer, da educação e da moradia, ao mesmo tempo em que se permitem pequenos prazeres ocasionais.

Na seção seguinte analisaremos as tipificações e juízos morais sobre as origens e os destinos do dinheiro em diferentes setores sociais.

\section{TIPIFICAÇÕES E JUÍZOS MORAIS SOBRE O DINHEIRO}

Manuel, 48 anos, presidente de uma empresa de transporte, três filhas.

A família de Manuel é uma família biparental de classe média alta que reside no bairro de San Isidro, ao norte da conurbação. ${ }^{12}$ Em sua empresa, Manuel tem aproximadamente cinquenta pessoas sob seu comando. Sua esposa tem 46 anos e trabalha no ramo imobiliário. Vivem com suas três filhas, de I4, I6 e I 8 anos. As duas menores estão cursando o ensino médio em um colégio bilíngue de período integral em San Isidro, enquanto a mais velha, vinda do mesmo colégio, estuda arquitetura na Universidade de Buenos Aires.

A entrevista foi feita no seu local de trabalho, em janeiro de 2013. Justamente no dia anterior Manuel tinha sido assaltado ao voltar do centro financeiro de Buenos Aires, onde comprou reais para viajar para o Brasil com sua família. Também lhe roubaram os documentos do automóvel que acabara de comprar para a filha mais velha, era uma "surpresa para quando voltasse das férias". Mostrou-se preocupado com a insegurança e os roubos, que relaciona com a corrupção e a "parte desonesta que temos todos os argentinos". No entanto, ao interpretar a própria trajetória laboral, Manuel ressaltou seu compromisso com o trabalho e o esforço como explicativo de uma mobilidade intrageracional ascendente e de longo alcance: "eu trabalho desde os I4, I5 anos. Trabalhava limpando terrenos baldios, trabalhei de garçom, trabalhei de sorveteiro, vendi estampitas [santinhos] de porta em porta. E aqui comecei como aprendiz". Considerando o seu esforço para ganhar dinheiro, vemos aparecer uma ideia de meritocracia, valorizada como modelo de ordem social: aqueles que mais se esforçam deveriam obter reconhecimento econômico e status em suas ocupações. Entretanto, a realidade impõe outros critérios: "outro grande problema que nós argentinos temos é: se castiga o que se esforça 
no trabalho. [...] Um garoto que trabalha bem merece um salário maior do que aquele que trabalha mal. Mas hoje, tudo, tudo, tudo protege o que trabalha mal".

Manuel considera que há valores morais como o "esforço" e o "trabalho" que definem as formas legítimas de transferência de dinheiro. Ao falar da vida cotidiana das camadas populares, associa estes valores com a história de uma concorrente em um programa de televisão:

Houve uma moça que se apresentou, muito humilde, da zona de José C. Paz, a garota vende chipa na estação de trem de José C. Paz e com isso vive, ou seja, realmente é ter vontade de viver e de se alimentar porque... O que acontece é que você sustenta as pessoas no limite, tem os catadores, uma coisa destroçada, não? Ou com o salário dado, não? Creio que o trabalho é ensinar a trabalhar.

Este exemplo lhe serve para desaprovar fortemente o "salário dado" que "sustenta" gente "destroçada", em contraposição ao "dinheiro ganho" com "vontade", com "trabalho", com "esforço". Assim tipifica os dinheiros transferidos por políticas sociais, aludindo à falta de interesse e responsabilidade, ao desperdício, em resumo, uma atitude econômica que na medida em que não está dirigida ao investimento não é saudável. Compara os presentes para seus filhos com os subsídios e planos sociais e, em ambos os casos, justifica sua restrição como um processo educativo:

Não se pode dar tudo a eles porque se cai em uma situação que... o mesmo em certa medida o Governo dá aos que não têm trabalho, ou acesso ao trabalho, dizem. Deveriam dar a eles acesso ao trabalho, não? Não dar-lhes planos que é um pouco o que... se tudo chega com um esforço, e tudo com um esforço é valorizado. Se não o valorizamos, não se chega lá. É como ganhar o dinheiro na loteria ou realmente trabalhando. Quando se ganha o dinheiro na loteria, 80\% você estoura em uma semana ? É isso, você vai ao cassino, ganha, você convida para comer todos os amigos, você detona o dinheiro em um minuto. Agora, quando é com esforço você pensa duas vezes, não? Você pensa um pouco melhor, e como investi-lo. Com os filhos é o mesmo, você tem uma questão de que eles têm que ganhá-lo. Ter uma responsabilidade com o estudo, ter uma responsabilidade com a família.

Deste ponto de vista, tanto Manuel quanto sua mulher vão medindo e limitando os presentes em dinheiro a seus filhos sob a premissa de que o dinheiro deve ser ganho com "responsabilidade", marcando uma origem que deve condizer com as atividades e prioridades culturais da classe média. Esses usos o ajudam a construir juízos de valor sobre as decisões econômicas dos motoristas da empresa na qual trabalha (tipificados como gente de "baixa educação"):

Tratamos de orientá-los para que comprem sua casa, para que façam os filhos estudar, entende? É gente que ganha um salário muito bom, hein... de modo que... bom, me parece um desperdício realmente que, que... Porque essa gente... você vê que a baixa educação, eles torram o dinheiro. ${ }^{14}$ 
Seguindo este modelo meritocrático de organização social que observamos nas apreciações de Manuel, podemos voltar aos relatos de Andrea, uma de nossas entrevistadas de classe média, apresentada na parte anterior.

Nos registros da entrevista de Andrea, a "gente dos países limítrofes", i.e. os imigrantes, ocupa um lugar especial. Ela aponta sua presença no bairro de Constitución, que vê deteriorado, e também se mostra incomodada por eles se aproveitarem das oportunidades na cidade, como a utilização dos serviços públicos e gratuitos de saúde e educação: "há toda uma transmigração de gente, igual às pessoas do interior. Não é que querem vir para cá por diversão. Vêm para cá porque estão buscando oportunidades, então se as tivessem em seu [país], em sua província de origem, não sofreriam". Da mesma forma, seu relato explicita outras tensões relativas aos imigrantes. Andrea explica as dificuldades que encontra para se classificar como membro da classe média já que sua pauta de consumo e sua carga laboral e tributária não estão de acordo com as expectativas relacionadas com o seu nível educacional universitário. ${ }^{15}$ Atualmente, ela se percebe como socialmente desclassificada e vive isto com sofrimento. Certos indicadores relativos ao consumo lhe servem para comparar sua situação com a de seus pais durante sua juventude, como o serviço doméstico, a cobertura de saúde, as férias e o automóvel:

A mim [meus pais] me disseram, me informaram, que eu era classe média com aspirações... hoje ficaram as aspirações, como a nível país. [...] em relação a eles [meus pais] tenho duas questões: uma, minha mãe, digamos, nem sempre [mas] tinha uma pessoa que regularmente a ajudava, pelo menos semanalmente, nas tarefas domésticas. E, depois, principalmente, tinham cobertura de saúde... e outra coisa que perdi, que a qualquer momento estou para recuperar [risos] são as férias porque realmente, ou seja, este ano me permiti ir por uma semana a San Clemente del Tuyú e... [risos] patético. [...] Outra coisa também que a qualquer momento recupero ... o automóvel! O automóvel. Não eu, porque não dirijo, [mas] meu marido... ele sente mais falta do carro do que eu [...]. Com relação a meus pais, meus pais tinham automóvel, meus pais tinham cobertura de saúde, iam de férias, ainda que a cada dois ou três anos, ou seja ..., evidentemente não é uma questão minha, há outras pessoas que estão na mesma situação.

Segundo Andrea, seus pais lhe teriam transmitido a ideia de que a aquisição de credenciais educacionais garantiria o acesso a ocupações não manuais relacionadas com um status e capacidade de consumo maior que o atual. Assim, Andrea vive uma situação pessoal contraditória ao ver que sua condição financeira não corresponde ao ideal meritocrático recebido de seus pais. Um maior nível educacional, um trabalho mais qualificado e uma maior carga tributária não lhe proporcionaram mais dinheiro nem qualidade de vida melhor do que a de seus vizinhos imigrantes. Vejamos o caso de Oscar, 38 anos, pedreiro e pai de três filhos, e beneficiário de distintos programas de TMC:

[...] trabalho de segunda a segunda [risos]. Ou seja, eu não me situo em nenhum lugar, ou seja a nível cultural e a nível de estudos poderia dizer universitário 


\begin{abstract}
completo, seja a letra fria. Mas pelo lugar onde vivo e pela vida que levo e tudo mais, poderia dizer que sou de classe baixa. (...) essas classes estanques que em determinado momento foram criadas, ficaram... ficaram no tempo. Aqui há pessoas que não se sabe a que se dedicam e passam com camionetes $4 \mathrm{x} 4$ que custam mais der 30.000 pesos, então, o que é? Classe alta ou classe baixa? Trabalho não têm, pagam impostos? Não. Então, é relativo.
\end{abstract}

Oscar vive com sua mulher Naty, de 35 anos, e seus três filhos: Natalia (6), Matías (4) e Román (I). Atualmente está reformando sua pequena casa de tijolo sem reboco, telhado de chapa metálica e de apenas um ambiente, localizada no "beco dos tucumanos", como costumam chamá-lo os vizinhos da Favela Asunción. Essa denominação guarda uma estreita relação com o lugar de origem da maioria dos vizinhos que ali residem: a província de Tucumán, ao norte da República Argentina.

O orçamento familiar é composto, na sua maioria, por rendimentos oriundos de programas de TMC. Sua mulher é beneficiária da AUH por causa dos seus três filhos, enquanto Oscar faz parte do programa "Argentina Trabaja” há aproximadamente quatro anos. A somatória dessas diferentes receitas de dinheiro por transferência direta das políticas sociais deve chegar a 2.600 pesos aproximadamente. Ademais, se destaca o ganho que Oscar considera como "forte": "os bicos na construção".

Oscar classifica e distingue os recursos de seu orçamento da seguinte maneira. Como já mencionamos, "o ganho forte" vem dos trabalhos que faz "por fora, na construção": "agora estou pegando um trabalhinho de ampliação em cima de uma funerária. Cobrei 5 lucas [5.00o pesos] por todo o trabalho". Esse ganho resulta "forte" em oposição ao dinheiro proveniente dos programas de TMC: "a concessão (AUH) é dinheiro para a malaria. Eu digo à Naty que o guarde para chegar ao fim do mês... para a malaria, ${ }^{16}$ para quando você não tem um mango, ${ }^{18}$ para comprar alguma comida que falte no fim do mês". Por outra parte, ao se referir ao dinheiro proveniente do programa "Argentina Trabaja", Oscar faz avaliações similares às de Manuel:

Por um lado, é pouco dinheiro... I.500 mangos [pesos] para as pessoas não serve para nada e o Governo sabe, mas se fazem todos de distraídos. Mas não é só esse o problema... eu já estou cansado, não me irrito mais. São todos vagabundos, ninguém quer trabalhar, só se preocupam com que chegue o dia cinco de cada mês e que tenham o dinheiro depositado no banco. Depois gastam a rodo na noite, compram bobagens.

Ao longo dos quatro anos de trabalho, Oscar estabeleceu diversos contatos pessoais a partir do programa "Argentina Trabaja" e sonha "ser empregado municipal". Iniciou uma relação de estreita proximidade com um empregado municipal de certa hierarquia em uma das principais administrações do distrito: "agora estou falando com Santillan, da administração de Domínico. Talvez consiga que me efetive no município o ano que vem". Suas expectativas guar- 
dam relação com o dinheiro a que poderia chegar a ter acesso como empregado municipal, e as oportunidades que tais somas significariam:

O do plano por I.500 [pesos] já foi. Santillan trabalha cinco ou seis horas por dia e uma vez por semana nem aparece na repartição. Além disso, anda o dia todo no carro que lhe dão aqui, com ar condicionado, supervisionando os trabalhos. Imagina... você nunca vai vê-lo sujo, sempre com uma camisa diferente. Deve receber 8 ou 9 lucas [8.000 ou 9.000 pesos], agora vai quinze dias para a costa. Eu vou fazer o possível para que ele me coloque lá dentro.

Otilia, 5 I anos, casada e mãe de quatro filhos, beneficiária de distintos programas de TMC.

Otilia é oriunda da Província de Chaco, ao Norte da Argentina. Está casada há mais de 25 anos com Carlitos, 52, e tem quatro filhos: Ezequiel (22), Erick (I7) Richard (I I) e Tiziana (6). Carlitos há dezessete anos trabalha em uma fábrica de plásticos a uns dez quarteirões do bairro. Há aproximadamente quatro meses Otilia se incorporou ao programa "Argentina Trabaja": "agora que comecei a trabalhar meu salariozinho é uma ajuda [...] há tantos anos que não trabalhava", costumava dizer Otilia.

Até meados do ano de 2005 , ela e sua família viveram em um dos becos da Favela Asunción, talvez o mais significativo, conhecido pelos vizinhos como "o beco do T" em referência à sua forma de letra " $T$ ". Atualmente residem em uma das novas moradias sociais construídas durante o processo de urbanização. Otilia recorda "a favela" como um lugar marcado pela pobreza e a privação material:

Eu digo para os meninos que há que cuidar da casinha: Você sabe como vivíamos lá? Dormíamos todos em um quarto, com colchões que, depois, pela manhã, eram levantados para virar mesa de jantar, não tínhamos nem para um móvel. E houve épocas, como em 200I, que interrompiam o trabalho de Carlitos constantemente na fábrica e tinha que ir ao mercado central onde catava fruta e verdura.

Nos encontros e conversações com ela, reaparecem constantemente histórias relacionadas a sua vida na província do Chaco e, posteriormente, à "vida na favela":

Eu digo a eles que têm que estudar, ter seu futuro. Eu lá no Chaco não pude continuar estudando, você não sabe quanto me dói. Tive que trabalhar desde muito pequena com a cana de açúcar, vim trabalhar jovenzinha em casa de família em Buenos Aires. Aqui pudemos ter uma cama, mesas, cadeiras, um fogão, geladeira, tudo isso conseguimos ter.

O relato de seu progresso econômico e social inclui a preocupação com a possibilidade de que seus filhos "possam desfrutar": "agora, aqui, com o dinheiro há que investir. Agora, como digo a eles: isto é tudo para vocês" ? Ela mostra um claro interesse por poder transmitir a seus filhos valores morais correspondentes com a possibilidade de um futuro econômico próspero: 


\begin{abstract}
Aqui há muitos jovens que não têm nada em casa para comer, mas andam super bem vestidos. Eu sempre digo a eles, quando terminamos de comer: "vão economizando, vão juntando, no dia de amanhã vocês podem comprar um terreno e podem também construir sua casinha, e já não vão mais precisar morar comigo. Quando já tenham seu marido e mulher, quando já estejam no que é deles". Ontem estava falando com Ezequiel "querido, você vai se livrar das contas agora", ${ }^{18}$ porque está de férias agora. "Economiza", digo a ele, "mesmo que sejam 200 ou 300 pesos já podem poupar". Ou olha um terreno "bom, eu gosto daqui", e começa a pagar a prestação, assim no dia de amanhã você faz a sua casinha.
\end{abstract}

Otilia tenta transmitir a seus filhos determinados significados e usos do dinheiro que, em certa medida, os diferenciem de outros próximos no espaço social e os aproximem das expectativas de progresso e crescimento econômico dos setores médios: "porque, por mais pobre que sejam, eles aspiram, anseiam, sonham ter, e isso é bom. Isso te ajuda muito, te dá muito alento ver que não esbanjam o dinheiro. Se esforçam e é bom saber que vão ter no dia de amanhã".

Simmel se referia à "falta de caráter" como uma qualidade muito positiva do dinheiro: "no âmbito dos fenômenos, só o dinheiro se libera de tudo a ponto de passar a estar completamente determinado por sua quantia" (Simmel apud Poggi, 2006: I 2I). No entanto, os relatos anteriores nos mostram vários exemplos de como se atribuem sentidos e valores ao dinheiro de acordo com suas origens e usos, mais do que por sua quantia.

Ao nos determos nos setores médios, os relatos de Manuel e Andrea ressaltam o valor de um "dinheiro ganho" (Wilkis, 2013) baseado no "trabalho" e na "responsabilidade", em detrimento do dinheiro proveniente de subsídios e transferências monetárias. Em função dessas diferentes origens do dinheiro, Manuel tipifica também diferentes destinos do dinheiro: enquanto o dinheiro ganho é investido na casa e no estudo, o dinheiro dado àqueles que não se esforçam se torra, se desperdiça. Esta marca distintiva da classe média remete tanto às suas histórias de origem, bem como às suas credenciais de educação e outras conquistas conseguidas por mérito próprio. Porém, como vemos no relato de Andrea, suas conquistas educacionais e seu esforço laboral não resultaram para ela em renda maior. Aborrece-se ao ver que seus vizinhos, que não trabalham nem pagam impostos, têm nível de vida superior ao dela. Assim, dá a entender que a origem desse dinheiro é ilegal e, portanto, seu destino, ilegítimo.

Nos registros etnográficos de Otilia e Oscar observamos situações biográficas marcadas pela carência e pela precariedade, por nível educacional baixo ou inclusive sem estudos formais e inserção subordinada na estrutura ocupacional. Estas situações biográficas implicam a emergência de outras necessidades e origens do dinheiro mais heterogêneas, bem como destinos mais imediatos em sua vida cotidiana. Em suas variadas fontes de ganhos familiares depreendemos o esforço para "não ter tempos economicamente mortos" 
(Wikis, 2013: I06) e em seu horizonte de expectativas de futuro desponta o "ir poupando" ou "juntando", economizando paulatinamente, já que os grandes investimentos da classe média não estão ao seu alcance.

Suas práticas econômicas e os usos que fazem do dinheiro se contrapõem à "falta de caráter" que indicava Simmel; antes, se aproximam da ideia do dinheiro como uma lupa através da qual os diferentes grupos sociais se observam e observam seu entorno (Sautu, 200I: 52). Os significados associados ao dinheiro e as apreciações sobre suas origens e seus usos permitem a setores médios e populares tipificar suas práticas e as de outros, bem como emitir juízos e avaliações morais sobre atores que ocupam posição mais ou menos próxima no espaço social. ${ }^{19}$ Os registros das classes médias são construídos sobre certa desvalorização dos setores populares, reproduzindo representações da própria classe de pertencimento e ideais meritocráticos. Nos setores populares, os registros dão conta de uma hierarquização das próprias decisões e práticas econômicas com base numa depreciação daqueles mais próximos na escala social, que, embora ganhando dinheiro da mesma maneira, escolhem para este outros destinos menos valorizados como "andar bem vestido" ou gastá-lo "a rodo na noite". Com isso queremos assinalar que, quando falam de dinheiro, tanto as classes médias quanto os setores populares dizem algo sobre a ordem social.

\section{CONCLUSÕES}

Neste artigo pudemos observar que as famílias de setores médios e setores populares dão conta razoavelmente, no sentido schutziano, de sua situação biograficamente determinada. ${ }^{20}$ Isso fica evidente tanto no estudo sobre os significados do dinheiro proveniente das políticas sociais quanto no estudo sobre o senso comum e as práticas cotidianas da classe média no que concerne a educação e saúde. Em diferentes populações, ambos os estudos abordaram o dinheiro como um poderoso instrumento de desigualdade, para além dos interesses e moralidades de cada família e setor social de pertencimento. Os rendimentos funcionam como limitantes das possibilidades que as famílias têm frente a suas necessidades. Sua capacidade econômica lhes impõe margens de comportamentos. Assim, o dinheiro é uma das maneiras com que os entrevistados interpretam o alcance de suas ações, definindo contextualmente um mundo acessível para si e para suas famílias.

No entanto, há as valorações normativas. Os relatos acerca dos orçamentos familiares, gastos e decisões se encontram carregados de valores e símbolos herdados e compartilhados. Em setores populares vimos que resolver e/ou melhorar a situação habitacional é uma prioridade, é o melhor investimento que podem deixar para seus filhos. Em troca, a prioridade conferida às questões de saúde e educação nas famílias de classe média resulta em um 
elemento fundamental de sua posição de classe, pois sua situação habitacional já se encontra resolvida desde gerações anteriores e, portanto, é dada por assegurada até segunda ordem.

Além disso, observamos que tanto as famílias de setores médios quanto as de setores populares estabelecem diferença entre "bons" e "maus" gastos, em termos de tipificações de valores, atitudes e comportamentos relacionados ao dinheiro. Estas tipificações em relação aos diferentes significados e usos do dinheiro medeiam sua reflexão acerca da sociedade. Com suas decisões econômicas e práticas cotidianas, utilizam estas noções de senso comum para demarcar limites entre Nós e Outras famílias. Em ambos os setores sociais, os entrevistados associam o dinheiro ao esforço cotidiano para reproduzir ou melhorar sua posição de classe e também a sua responsabilidade pelo futuro de seus filhos. Os pais e mães de classe média asseguram não estarem dispostos a arriscar o futuro por gastos imediatos com o consumo e o entretenimento. Em vez disso, planejam seus gastos prioritários e orientam os esforços familiares para a consecução de metas relacionadas com a saúde e a educação de sua família. Os pais e mães de setores populares também distinguem entre gastos imediatos e investimentos para o futuro. Associam os primeiros com o consumo de bens secundários e indumentária, enquanto hierarquizam suas próprias práticas de investimento no equipamento da moradia a partir do acesso a créditos e pagamentos a prestação e, de maneira secundária, as pequenas poupanças de seus filhos pensando no "dia de amanhã".

Em ambos os estudos, o dinheiro serve aos entrevistados para explicar experiências e decisões da vida cotidiana; e também para realizar juízos e avaliações morais sobre os Outros. Seus discursos e suas tipificações estão carregados de valores e símbolos através dos quais se diferenciam e hierarquizam. Desse modo, o dinheiro "arrasta com ele hierarquias morais, desenha uma ordem social onde os sujeitos se situam" (Wilkis, 2013: 28).

Por último, estes resultados se baseiam em pesquisas realizadas a partir de uma perspectiva qualitativa, para compreender a posição, os sentimentos, as experiências e a cosmovisão dos atores sobre a realidade social (Patton, 2002). Essa perspectiva teórico-metodológica nos permitiu colocar em diálogo os resultados obtidos a partir do uso de diferentes métodos (entrevistas biográficas e etnografia) provenientes de diferentes tradições disciplinares (sociologia e antropologia social). A etnografia possibilitou a análise minuciosa dos orçamentos familiares e da multiplicidade de tensões e negociações existentes nos lares em torno do dinheiro. Ao mesmo tempo, as entrevistas biográficas nos permitiram relacionar práticas cotidianas e trajetórias familiares de classe em diferentes gerações. Como se sabe, estas decisões sobre o método e a seleção dos casos a serem examinados não só está sujeita aos outros elementos do desenho de investigação, como também a uma contínua negociação e reflexividade entre o pesquisador e seu universo de estudo (Maxwell, I996). Neste sentido, as 
entrevistas biográficas resultavam mais adequadas para a população de classe média que, preocupada com uma sensação de insegurança (Kessler, 2009), demonstrava maior reticência a abrir as portas de seus lares e franquear-nos informação sobre seus orçamentos familiares, bem como os nomes de instituições e pessoas com as que se vinculam em sua vida cotidiana. O fato de termos pesquisado o mesmo bairro anteriormente fez com que pudéssemos contar também com o recurso à etnografia realizada àquela época.

Finalmente, ambas as pesquisas conseguiram captar a percepção e juízos de valor de pessoas de diferentes setores sociais acerca dos significados e usos do dinheiro. Ao ressaltar que este diálogo interdisciplinar não foi apenas produtivo para complementar e comparar os resultados obtidos em diferentes populações da Área Metropolitana de Buenos Aires, seguindo Denzin (I970), defendemos seu potencial de ampliação do conceito de triangulação metodológica para além da medição, de modo a incluir também uma contínua triangulação de dados, de pesquisadores, de teorias e de metodologias a fim de produzir o conhecimento objetivo sempre problemático.

Recebido em 23/02/20I5 | Aprovado em 22/06/2015

Martín Hornes é doutorando em Sociologia na Universidad Nacional de San Martín (UNSAM) e bolsista do Consejo Nacional de Investigaciones Científicas y Técnicas (CONICET) com sede no Instituto de Altos Estudios Sociales, UNSAM, Buenos Aires, Argentina.

Mercedes Krause é doutoranda em Ciências Sociais na Universidad de Buenos Aires (UBA) e bolsista do Consejo Nacional de Investigaciones Científicas y Técnicas (CONICET) com sede no Instituto de Investigaciones Gino Germani, UBA, Buenos Aires, Argentina. 


\section{NOTAS}

I Em seu livro intitulado El significado social del dinero, Viviana Zelizer fala de uma noção de orçamentos organizada em torno da "marcação do dinheiro" no interior dos lares. A categoria de marcação alude a um conjunto de representações e práticas sobre o dinheiro - restrições sobre seu uso, ordenamento, modos de controle, lugares de disposição, rituais para sua apresentação ou delimitação para usos específicos - que atuam construindo o orçamento e "onde cada categoria possui regras próprias para o gasto dos fundos" (Zelizer, 2010: 47).

2 Partimos do pressuposto de que as classes sociais estabelecem condições básicas de existência ao abarcarem o poder de apropriação dos recursos materiais, o conhecimento e os direitos e privilégios que se dirimem no mercado (Marx, I980; Weber, I964; Wright, 2005). As classes sociais são construções coletivas com consequências sociais e individuais (Sautu, 20I I), já que condicionam a vida das pessoas, suas decisões e práticas cotidianas e, finalmente, seu destino.

3 Para salvaguardar a identidade e confidencialidade das pessoas que participaram de nossas respectivas pesquisas, os nomes próprios que utilizamos são fictícios.

4 Embora não discutido na análise, a classe média é uma categoria heterogênea, composta por três posições de classe: "Classe média profissional e managers", "Mediana e pequena burguesia" e "Classe média técnico-comercial-administrativa” (Sautu et al., 2007). Os dados sobre as famílias foram proporcionados pelas enquetes sobre Estratificação $e$ mobilidade social aplicadas pelo Centro de Estudios de Opinión Pública (CEDOP-UBA) em 2004, 2005 e 2007. Baseandonos em estudos quantitativos anteriores (Otero, 2008; Dalle, 2009; Rodríguez, 2009), selecionamos famílias com filhos menores e jovens e que tiveram ao menos um membro da geração anterior com inserção ocupacional na classe média, a fim de obter uma perspectiva ao mesmo tempo sincrônica e diacrônica dos mecanismos de reprodução social.

5 A Área Metropolitana de Buenos Aires (AMBA) está conformada pela Cidade Autônoma de Buenos Aires (CABA) e 24 municípios que compõem a conurbação, e conta com um 
total de 9.910.282 habitantes. O município de Avellaneda é o primeiro município localizado no sentido sul, limítrofe com a Cidade Autônoma de Buenos Aires. Ele possui uma superfície total de $54 \mathrm{~km}^{2}$, e uma população estimada em 350.000 habitantes, segundo o último censo populacional realizado pelo Instituto Nacional de Estadísticas y Censos (INDEC, 20IO).

6 Em 200I, a Argentina sofreu uma grande crise como consequência da reestruturação neoliberal e a saída, em dezembro de 200I, do regime de conversão entre o peso argentino e o dólar estadunidense. Seguiram-se vários anos de uma recessão econômica que afetou tanto os setores médios quanto os setores populares. Para mais informação sobre a discussão sobre as crenças e valores da classe média e suas condições empobrecidas de existência, ver Svampa (2000), Sautu (200I), Minujin \& Anguita (2004), Kessler \& Di Virgilio (2008) e Visacovsky (2010). Para mais informação sobre os altos níveis de pobreza e desocupação nos setores populares, assim como a recuperação dos salários familiares através de programas de TMC, ver Panigo \& Chena (20I I)

7 Trata-se de um programa de TMC dependente do Ministério de Desenvolvimento Social da República Argentina criado no ano 2008 e dirigido à população vulnerável maior de 18 anos que se encontre desocupada. Consiste em uma transferência de dinheiro líquido que atualmente chega a r.6oo pesos, condicionada ao cumprimento de uma contraprestação de serviços em alguma dependência municipal de governo. Para mais informação, consultar: $<$ http//:www.desarrollosocial.gob.ar/argentinatrabaja>

8 Inspirado em outras TMCs da região, como é o caso do programa Bolsa Família no Brasil, a AUH é uma transferência mensal de dinheiro dirigida aos trabalhadores informais ou precários que adquire condicionalidades similares às concessões familiares das quais gozam os trabalhadores pertencentes ao sistema contributivo (controles sanitários e assistência escolar). Para mais informações ver Hornes (20I5).

9 Para distintas etnografias econômicas centradas em finanças e endividamento dos setores populares, consultar o número especial da revista de Antropologia Social, Desacatos, $\mathrm{n}^{\circ} 44$ "Las deudas de los oprimidos en el imperio de la li- 
quidez", editada pelo Centro de Investigaciones y Estudios Superiores en Antropología Social (CIESAS). Disponível em: $<$ http://desacatos.ciesas.edu.mx/index.php/Desacatos $>$. Para o caso argentino, consultar Wilkis (2014).

Io O Plan Federal de Vivienda é a política de alcance nacional da área de moradias, sob alçada do Ministerio de Planificación Federal, Inversión Pública y Servicios da Nação Argentina. Os programas de urbanização, obra pública e infraestrutura são executados de forma descentralizada pelas distintas províncias (e os municípios), atuando o organismo nacional como controlador fiscal e de certificação e avanço de obras. Informação disponível na página $<$ http://www.minplan.gov.ar>.

I I Desde sua criação, em I994, o Plano Más Vida consistia numa intervenção nutricional materno-infantil, baseada na entrega diária de leite e uma cesta de alimentos entregue pelas trabalhadoras vizinhas (mais conhecidas como "manzaneras" e "comadres"). A partir do mês de março de 2008, o Plano Más Vida "introduz um sistema de pagamento de um subsídio não remunerado às famílias beneficiárias através da entrega de um cartão eletrônico destinado exclusivamente à compra de alimentos" (Dallorso, 20I0: I42).

I 2 O município de San Isidro é o segundo município no sentido norte da Grande Buenos Aires, a uns $20 \mathrm{~km}$ da Cidade Autônoma de Buenos Aires. Ele tem uma superfície total de $48 \mathrm{~km}^{2}$, e uma população estimada em 300 mil habitantes, segundo o último censo populacional realizado pelo Instituto Nacional de Estadísticas y Censos (INDEC, 20Io). É uma área que reflete a polaridade entre setores de alto status social e econômico e a favela La Cava, que se estende por uma área de uns ig hectares e conta com uma população aproximada de 8.500 pessoas.

I3 $\mathrm{Na}$ Argentina se conhece como "estampitas" as imagens devocionais impressas sobre cartolina.

I4 "La plata la quema" é uma gíria originada nas principais cidades do país que, neste caso em particular, assinala certo desperdício ou mau uso do dinheiro por parte dos setores populares.

I5 Essa dificuldade de autoidentificação dos setores médios já havia sido marcada por Germani com base em uma enquete realizada em I960, sobre uma amostra aleatória de 2.000 
famílias da Área Metropolitana de Buenos Aires (AMBA). Ao analisar as correlações entre Nível Econômico Social (média ponderada de indicadores de ocupação, salário, moradia e nível de consumo, e educação) e autoafiliação a classe, encontra que uma "proporção considerável" dos que registram NES médios, possuem indicadores "incongruentes" como altos níveis em educação e baixos níveis de renda. Nesses casos, a proporção de "desviados" com respeito à sua autoafiliação "adequada" tendia a se elevar (Germani, 20I0c: 233).

I6 Expressão que também remete ao lunfardo (linguagem popular) argentino. "Para la malaria" assinala a presença de um dinheiro de pouca quantidade, quase sem valor monetário, destinado a gastos menores de fim de mês.

I7 Expressão do lunfardo argentino utilizada para se referir ao dinheiro.

I8 As "cuentas" ou "encuentarse" são categorias nativas que se referem à aquisição de um crédito pessoal, geralmente destinado à compra de algum bem móvel ou mobiliário para o lar. Entre esses créditos se destacam os empréstimos das casas de vendas mais reconhecidas das localidades ou dos circuitos comerciais, como por exemplo: Credifácil, Corefín, Efectivo Sí etc. As palavras de Otilia também introduzem as representações morais negativas ligadas ao crédito, em contraposição a uma prática virtuosa da poupança nos setores médios, ambos os aspectos abordados por Luzzi (2013).

I9 Está fora do escopo deste trabalho abordar o debate emergente sobre uma sociologia e antropologia das moralidades. Para uma revisão da temática, ver Didier Fassin (2009). Para dois trabalhos etnográficos que indagam sobre as construções morais associadas ao universo da pobreza e dos beneficiários de seguros de desemprego, ver Tebet Marinis (20I4) e Dubois (20I4).

20 Segundo a fenomenologia social, as práticas do mundo da vida cotidiana respondem a uma sorte de lógica racional no plano de seu senso comum. Não é racional no sentido objetivo, mas, sim, no sentido subjetivo: "a 'ação racional', no plano do senso comum, é sempre ação dentro de um marco inquestionável e indeterminado de construções de tipicidades" (Schutz, 2003: 59). 


\section{REFERÊNCIAS BIBLIOGRÁFICAS}

Bloch, Maurice. (I989). The symbolism of money in Imerina. In: Bloch, Maurice \& Parry, Jonathan. Money and morality of exchange. Cambridge: Cambridge University Press, p. I65-igo.

Bloch, Maurice \& Parry, Jonathan (orgs.). (I989). Money and morality of exchange. Cambridge: Cambridge University Press.

Bohannan, Paul. (1967). The impact of money on an African subsistence economy. In: Dalton, George (org.). Tribal and peasant economies. Readings in economic anthropology. Nova York: The Natural History Press, p. I 23-I35.

Boyatzis, Richard E. (1998). Transforming qualitative information. Thousand Oaks: Sage.

Callon, Michel. (1998). The law of the markets. Oxford: Blackwell Publishers.

Dalle, Pablo. (2009). La movilidad social intergeneracional desde la clase trabajadora en el AMBA (2004-2005). Un análisis a nivel macro y micro social de los canales de ascenso, reproducción y descenso en la estructura de clases. Dissertação de Mestrado. FSOC/Universidad de Buenos Aires.

Dallorso, Nicolás. (2010). Manzaneras y comadres. Continuidades y transformaciones en las intervenciones gubernamentales: de la protección materno-infantil a las transferencias monetarias condicionadas (Conurbano Bonaerense 2005-2009). Dissertação de Doutorado. FSOC/Universidad de Buenos Aires.

Dalton, George. (1967). Primitive money. In: Tribal and peasant economies. Readings in economic anthropology. Nova York: The Natural History Press, p. 254-28I.

Denzin, Norman. (1970). The research act: a theoretical introduction to sociological methods. Nova York: Aldine.

Dodd, Nigel. (1994). The sociology of money: economics, reason \& contemporary society. Cambridge: Polity.

Dubois, Vincent. (20I4). The economic vulgate of welfare reform: elements for a socioanthropological critique. Current Anthropology, 55/S9, Crisis, value, and hope: rethinking the economy, p. Si38-Si46. 
Fassin, Didier. (2009). Les économies morales revisitées. Anales HSS, 6, p. I 237-I 266.

Figuiero, Pablo. (2013). Las lógicas sociales del consumo. El gasto improductivo en un asentamiento bonaerense. Buenos Aires: UNSAM Edital.

Gaggioli, Naymé. (2014). Economía en problemas: La agencia económica individual en tiempo de crisis. Revista Antípoda, I9, p. I89-2I5. Disponível em <http://antipoda.uniandes.edu.co/view.php/299/index.php?id=299>. Acesso em I 2 ago. 2014.

Germani, Gino. (20I0). La estratificación social y su evolución histórica en la Argentina. In: Mera, Carolina \& Rebón, Julián (orgs.). Gino Germani, la sociedad en cuestión: antología comentada. Buenos Aires: Consejo Latinoamericano de Ciencias Sociales, p. 210-239. Disponível em <http://biblioteca. clacso.edu.ar/gsdl/collect/clacso/index/assoc/D2980.dir/ Germani.pdf $>$. Acesso em I 2 ago. 2014.

Guyer, Jane. (org.). (I994). Money matters: instability, values and social payments in the modern history of West African communities. Londres: Elsevier.

Hart, Keith. (2004). Money: one anthropologist's view. In: Carrier, James (org.). A handbook of economic anthropology. Northampton, MA: Edward Elgar Publishing Limited, p. I60-I75.

Hornes, Martín. (20I5). Transferencias monetarias condicionadas: reflexiones sobre las políticas sociales y los significados del dinero. Revista Escenarios, 22 (no prelo).

Hornes, Martín. (20I4). Etnografiar políticas sociales. Reflexiones de una conversión disciplinar. Anuario de Antropología Social y Cultural en Uruguay, I2, p. 215-228. Disponível em <http://www.unesco.org/new/fileadmin/MULTIMEDIA/ FIELD/Montevideo/pdf/SHS-AnuarioAntropologia2oI 4.pdf>. Acesso em I 2 ago. 2014.

Hornes, Martín. (2013). Transferencias monetarias condicionadas (TMC): de los saberes expertos a los sentidos plurales del dinero. Dissertação de Mestrado. IDAES/Universidad Nacional de San Martín.

Hout, Michael. (2008). How class works: objective and subjective aspects of class since the I970s. In: Lareau, Annette \& Conley, Dalton (orgs.). Social class: how does it work? Nova York: Russell Sage Foundation, p. 25-64. 
INDEC. (20I0). Censo Nacional de Población, Hogares y Viviendas 20Io. Disponível em <http://www.sig.indec.gov.ar/ censo2010/>. Acesso em I2 ago. 20I4.

Kessler, Gabriel. (2009). El sentimiento de inseguridad. Buenos Aires: Siglo XXI.

Kessler, Gabriel \& Di Virgilio, María M. (2008). La nueva pobreza urbana: dinámica global, regional y argentina en las últimas dos décadas. Revista de la CEPAL, 95, p. 3 I50. Disponível em <http://www.eclac.cl/publicaciones/ $\mathrm{xml} / 9 / 33749 /$ RVE95KesslerDiVirgilio.pdf/>. Acesso em I 2 ago. 2014 .

Krause, Mercedes. (20I4). Un análisis del sentido que familias de clase media metropolitana le asignan a sus prácticas cotidianas en educación y salud. Dissertação de Mestrado. FSOC/ Universidad de Buenos Aires.

Lapavitsas, Costas. (2009). El capitalismo financiarizado. Expansión y crisis. Barcelona: Maia.

Lorenc Valcarce, Federico. (2012). Sociología de los mercados: modelos conceptuales y objetos empíricos en el estudio de las relaciones de intercambio. Papeles de Trabajo, 6/9, p. I4-36.

Luzzi, Mariana. (2013). Del contrato privado a la disputa pública: conflictos, representaciones y resignificaciones sobre el crédito y la deuda en el conflicto por los créditos hipotecarios (Argentina, 2002-2007). X Reunión de Antropología Social del Mercosur (RAM), Universidad Nacional de Córdoba.

Luzzi, Mariana. (2005). Réinventer le marché? Les clubs de tros face a la crise em Argentine. Paris: L'Harmattan.

Marins, Mani Tebet. (20I4). Repertórios morais e estratégias individuais de beneficiários e cadastradores do Bolsa Família. Sociologia \& Antropologia, 4/2, p. 543-562.

Marx, Karl. (I980 [I857]). Introducción general a la crítica de la economía política. Buenos Aires: Ediciones Carabela.

Maurer, Bill. (2012). The disunity of finance: alternative practices to western finance. In: Knorr-Cetinna, Karin \& Preda, Alex (orgs.). The Oxford handbook of the sociology of finance. Oxford: Oxford University Press, p. 413-430. 
Maxwell, Joseph. A. (1996). Qualitative research design. An interactive approach. Thousand Oaks: Sage.

Miller, Daniel. (1998). A theory of shopping. Nova York: Cornell University Press.

Minujin, Alberto \& Anguita, Eduardo (2004). La clase media: seducida y abandonada. Buenos Aires: Edhasa.

Motta, Eugenia. (20ı)). Trajetórias e transformações no mundo da Economia Solidária. Dissertação de Doutorado. PPGAS/Museu Nacional/Universidade Federal do Rio de Janeiro.

Müller, Lúcia. (20I4). Negotiating debts and gifts: financialization policies and the economic experiences of lowincome social groups in Brazil. Vibrant - Virtual Brazilian Anthropology, II/I, p. I9I-22I.

Neiburg, Federico. (2010). Os sentidos sociais da economia. In: Duarte, Luis Fernando Dias (org.). Horizontes das ciências sociais no Brasil: antropologia. São Paulo: ANPOCS.

Neiburg, Federico. (2008). Inflación, monedas enfermas y números públicos. Revista Crítica en Desarrollo, 2, p. 93- I30. Neiburg, Federico. (2007). As moedas doentes, os números públicos e a antropologia do dinheiro. Mana: Estudos de Antropologia Social, I3/I, p. I I9-I5I.

Neiburg, Federico. (2005). Inflación y crisis nacional. Culturas económicas y espacios públicos en la Argentina y Brasil. Anuario de Estudios Americanos, 62/I, p. I I3-I38.

Otero, María P. (2008). Educación universitaria y estructura social: tendencias de la expansión universitaria y sus efectos en la inserción ocupacional y pertenencia de clase de los graduados. Un estudio con datos secundarios de Argentina y del Área Metropolitana de Buenos Aires entre I989 y 2004. Dissertação de Mestrado. Escuela de Educación/Universidad de San Andrés.

Panigo, Demian \& Chena Pablo. (20I I). Del neo-mercantilismo al tipo de cambio múltiple para el desarrollo. Los dos modelos de la post-Convertibilidad. In: Chena, Pablo I. \& Crovetto, Norberto (orgs.). Ensayos en honor a Marcelo Diamand. Las raíces del nuevo modelo de desarrollo argentino y del pensamiento económico nacional. Buenos Aires: Miño y Dávila/Universidad Nacional de Moreno/CEIL-PIETTE-CONICET. 
Patton, Michael Q. (2002). Qualitative research \& evaluation methods. Thousand Oaks: Sage.

Poggi, Gianfranco. (2006). Dinero y modernidad: la filosofía del dinero de Georg Simmel. Buenos Aires: Nueva Visión.

Rodríguez, Santiago. (2009). Dinámica matrimonial en Argentina (2003-2004): un análisis de homogamia/heterogamia educacional y de clase social. Dissertação de Mestrado. FSOC/ Universidad de Buenos Aires.

Sautu, Ruth. (20I I). El análisis de las clases sociales: teorías y metodologías. Buenos Aires: Luxemburg.

Sautu, Ruth. (200I). La gente sabe: interpretaciones de la clase media acerca de la libertad, la igualdad, el éxito y la justicia. Buenos Aires: Lumiere.

Sautu, Ruth et al.. (2007). La construcción de un esquema de clases a partir de datos secundarios. Documento de Cátedra $\mathrm{N}^{\circ}$ 33. Buenos Aires: Cátedra de Metodología y Técnicas de la Investigación Social I, II y III dirigida por Ruth Sautu de la Carrera de Sociología, Facultad de Ciencias Sociales, Universidad de Buenos Aires.

Schutz, Alfred. (2003). El problema de la realidad social: Escritos I. Buenos Aires: Amorrortu.

Svampa, Maristella (2000). Desde abajo. La transformación de las identidades sociales. Buenos Aires: Editorial Biblos.

Théret, Bruno. (2008). Os três estados da moeda. Abordagem interdisciplinar do fato monetário. Economia e Sociedade, I7/I, p. I-28.

Théret, Bruno. (2007). La monnaie dévoilee par ses crises. Volume II. Crises monetaires en Russie et en Allemagne au XX siécle. Paris: Editions de EHESS.

Visacovsky, Sergio E. (2010). "Hasta la próxima crisis". Historia clínica, virtudes genealógicas y la identidad de clase media entre los afectados por la debacle financiera en la Argentina (2001-2002). Documento de Trabajo del CIDE, 68. México: Centro de Investigación y Docencia Económicas.

Weber, Florence \& Dufy, Caroline. (2009). Más allá de la Gran División. Sociología, economía y etnografía. Buenos Aires: Antropofagia. 
Weber, Florence. (2002). Práticas económicas e formas ordinárias de cálculo. Mana: Estudos de Antropologia Social, $8 / 2$, p. I5I-I 82 .

Weber, Max. (I964). Economía y sociedad. México: Fondo de Cultura Económica.

Wilkis, Ariel. (20I4). Sociología del crédito y economía de las clases populares. Revista Mexicana de Sociología, 76, p. $225-252$.

Wilkis, Ariel. (2013). Las sospechas del dinero. Moral y economía en el mundo popular. Buenos Aires: Paidós.

Wright, Erik. O. (2005). Approaches to class analysis. Nova York: Cambridge University.

Zelizer, Viviana. (20I I). El significado social del dinero. Buenos Aires: Fondo de Cultura Económica.

Zelizer, Viviana. (2009). La negociación de la intimidad. Buenos Aires: Fondo de Cultura Económica. 


\section{SIGNIFICADOS E USOS DO DINHEIRO: SETORES MÉDIOS E POPULARES DE BUENOS AIRES}

O artigo analisa significados e usos sociais do dinheiro em setores médios e populares da Área Metropolitana de Buenos Aires na perspectiva dos estudos sociais da economia. Resulta do diálogo entre dois trabalhos de pesquisa empírica realizados entre 2009 e 2014 . Primeiro, identificamos formas de marcação do dinheiro para mostrar como os distintos atores organizam seus orçamentos a partir das categorias do senso comum. Em seguida analisamos as avaliações morais feitas pelos participantes de ambos os estudos sobre as origens do dinheiro, demonstrando como distintas tipificações e juízos morais incidem sobre seus respectivos usos. Na última parte, concluímos como os esquemas diferenciados de percepção e apreciação nos permitem observar sentidos e usos plurais do dinheiro em setores médios e populares. Refletimos também sobre a potencialidade da integração interdisciplinar de metodologias e dados para a investigação nas ciências sociais.

\section{MEANINGS AND USES OF MONEY: MIDDLE AND WORKING CLASS SECTORS IN BUENOS AIRES}

Palavras-chave:

Senso comum; Significados e usos do dinheiro; Classes sociais; Transferências Monetárias Condicionadas; Argentina.

Keywords:

Common sense;

Uses of money; Social classes; Conditional cash transfers; Argentina. 